\title{
ON THE SPIRAL GROWTH OF THE INNER SURFACE OF THE CALCITIC SHELL, Ostrea gigas-II.*
}

\author{
Koji WADA** \\ (Received Feb. 11, 1963)
}

In the preceding paper, the author has discussed the very important differences between the spiral growths of the aragonitic and calcitic shells, and suggested that a definite diffusion of the mother fluid existed on inner shell surface is favored by moving of the mantle in the direction of its own elongation, where concentration gradients assume to occur. Furthermore the differences between aragonitic and calcitic shells may have been due to those of the crystal system to which both the minerals belong. We can, however, hardly draw a certain conclusion at once, since we have no sufficient fundamental knowledges about the mineralization of molluscan shells on ecological and taxonomical points of view.

In a series of biomineralogical studies on molluscan shells, the author would first try to take an abundance of observations on mineralization and development of shells.

\section{Material and Methods}

Observations were carried with the right valve of Ostrea gigas Thunberg from Ago Bay of Mie Prefecture in Japan through 1962. The inner surface of the shell from which the soft body was removed, was washed in distilled water, and was examined by the same techniques used in the preceding investigation ${ }^{57}$ to observe growth and aggregation of crystals.

\section{Observations}

The shell valves of Ostrea gigas possess two different layers consisting of the outer prismatic and the inner foliated structures, besides these lusterless chalky deposits distribute at various parts in the inner layer. The foliated layer which has been well known as calcitostracum or subnacreous showed local peculiar conditions of rather regular extinction in sections parallel and vertical to the inner shell surface under crossed nicols. That is, there are extinctions nearly vertical to mineral lamellae in vertical sections, while in parallel sections, the extinction is alike exclusively in the horizontal growth direction of the shell in marginal areas but will usually radiate around the center in growth pyramids. And there are various ex-

* Contribution No. 101 from National Pearl Res. Lab.

** National Pearl Res. Lab. (和田浩爾, 国立真珠研究所) 
tinctions in the boundary between adjacent pyramids. As in the layer of Anomia lischkei, the parallel slices were revealed the directions image cutting obliquely the optic axes of uniaxial crystals. This suggests us the optic axis which is not quite vertical but somewhat oblique to inner shell surfaces.

A lot of growth pyramids just like the contour lines showing mountain chain of a map may be developed over the limited area from the posterior adductor muscle impression to the hinge. Under low magnifications, we will be able to find numerous radial lines emitted from the top of a pyramid and concentric lines crossed the radial ones, as shown in Fig. 1. The radial pattern is associated with orientation of foliated

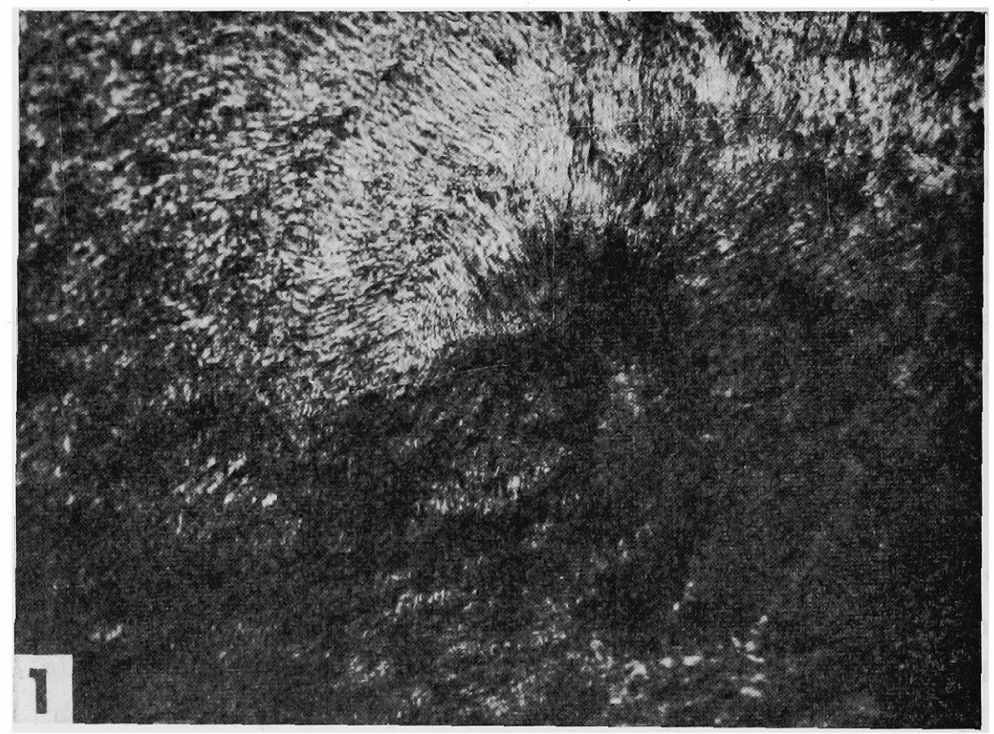

Fig. 1. A growth pyramid developing on the inner shell surface. $\times 150$

crystals radially elongated from the center, while the concentric one is provided with growth front of mineral lamellae, i.e., free side planes of mineral crystals, built up calcitostracum. Moreover the radial pattern is considerable to suggest the directions of horizontal growth of the layer since the orientation of diffusion of the pattern may be consistently coincided with the horizontal growth direction in marginal areas of the valves, and the height of steps, i.e., the concentric pattern, seen on the inclined plane of a growth pyramid is corresponded with the thickness of an elemental mineral lamella, about $0.26-0.37 \mu$.

Fig. 2 shows the tabular idiomorphic shape of the calcite, whose flat plane parallel to the paper is corresponded with the (0001) plane of calcite, as in the Anomia shell, grown on the inner surface of the foliated layer of $O$. gigas. The particle size of calcite of the shell in question here is considerably small compared with that of the Anomia shell, and is usually smaller than $8 \mu$. Distribution of angles in the basal 


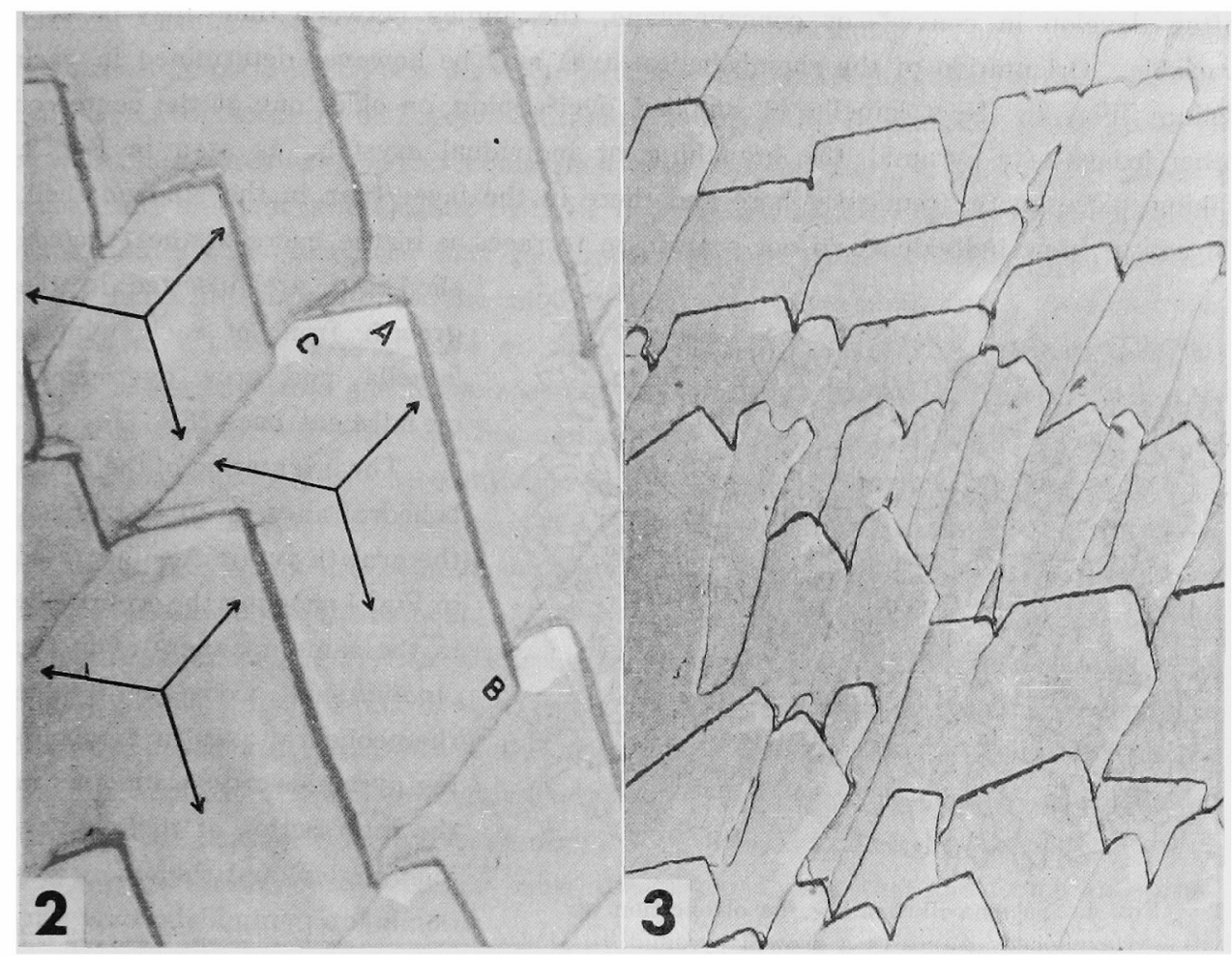

Fig. 2. Rhombohedral axes drawing in the basal plane of tabular idiomorphic crystals with well-developed faces. $\times 10,000$

Fig. 3. Showing the branching and overlapping of individual crystals. $\times 10,000$

plane is investigated from several electron micrographs and is shown in Table 1. Generally speaking, from the reasons pointed out by TuJII et al. ${ }^{3)}$ and $\mathrm{WADA}^{51}$, it is presumably considered that the angles of $90^{\circ}, 120^{\circ}$ and $150^{\circ}$ are the true angles and the side planes are between $(10 \overline{1} 0)$ and $(11 \overline{2} 0)$. But side planes with more high-index are possible to take place in there. In any case of them, since the side planes very

Table 1. The values of angles distributed in the basal plane of calcite (A, B and $\mathrm{C}$ are indicated in Fig. 2)

\begin{tabular}{c|c|c|c|c|c}
\hline \multicolumn{2}{c|}{ Angle A } & \multicolumn{2}{c|}{ Angle B } & \multicolumn{2}{c}{ Angle $\mathrm{C}$} \\
\cline { 5 - 6 } \cline { 5 - 6 } Degree & Frequency & Degree & Frequency & Degree & Frequency \\
\hline $81-85$ & 6 & $111-115$ & 0 & $126-130$ & 1 \\
$86-90$ & 10 & $116-120$ & 3 & $131-135$ & 3 \\
$91-95$ & 15 & $121-125$ & 22 & $136-140$ & 6 \\
$96-100$ & 14 & $126-130$ & 6 & $141-145$ & 7 \\
$101-105$ & 1 & $131-135$ & 2 & $146-150$ & 3 \\
$106-110$ & 0 & $136-140$ & 0 & $151-155$ & 1 \\
\hline
\end{tabular}


often develop in convex- or concave-plane, the angles between them may be very variable. Orientation of the rhombohedral axes may be however determined in each folium (Fig. 2). New lamella is supplied overlapping on older one at the center or other ledges of a pyramid, the branching of individual crystals, as seen in Fig. 3, taking place more frequently here and there in the layer than in the Anomia shell. Of course, new individuals do not scatter on terraces as in the nacre of the Pinctada

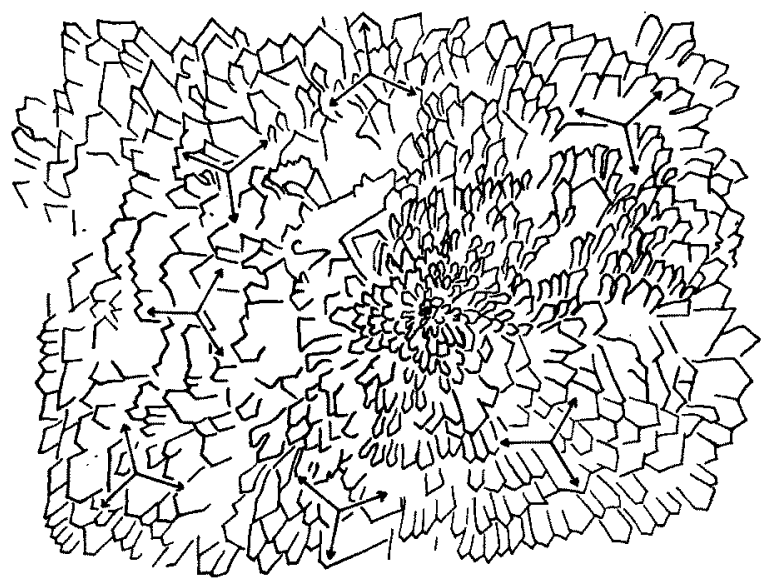

Fig. 4. Schema illustrating the orientation of rhombohedral axes in a growth pyramid. shell but are insetted in the growth front of each mineral lamella, and grow overlapping on adjacent ones (Fig. 3).

The orientation of the rhombohedral axes in an instance of the growth pyramid is illustrated in Fig. 4 showing the occurrence in the same manners as in the Anomia shell. Consequently, the rhombohedral axes in neigbouring pyramids cross each other in the intersection of them at various angles, and then more predominant pyramid become surpass other ones.

\section{Discussion}

The american oyster, Crassostrea virginica, has been used by Tusin et al..$^{\text {a) }}$ and WATABE et al. ${ }^{7)}$ to make clear the mechanism of crystal growth of calcite on the inner shell surface. Habit, growth and aggregation of calcite crystals on the shell of the another oyster, Ostrea gigas, examined here are essentially indistinguishable from those of the above mentioned oyster, and are similar to those of the Anomia shell (WADA, 1963). The orientation of the calcite crystals is very variable but statistically alike in definite directions; i.e., one of their rhombohedral axes running parallel with the horizontal growth direction of calcitostracum in margin of the shell, radiating spirally or directly around the top of a growth pyramid where we can go down step by step towards its shirts. Such radial orientation of the rhombohedral axes may give the X-ray diffraction pattern produced by the area $\mathrm{A}$ of the shell in Text-fig. 10 (WADA, 1961, p. 728).

Molluscan shells are non-living matters, though are a proper complex system built up of organic and inorganic substances produced by living matters. Accordingly, the occurrence of them assumes to take place under the biological and physical formulae. Here one element of growth of shells must be mainly determined by 
biological formulae and the other partially by physical formulae. The evidence is one of the most important subjects for biomineralogy and differentiation as seen in the shell valves of modern molluscs. Individual crystals in the similar layer seem to grow in same manners in no connection with species and moreover, the growth mechanisms of them is analogous to those of minerals in inanimate objects as a rule (WADA, 1961), which suggests that the crystal growth itself is rather governed by physicochemical conditions of the mother fluid, i.e., physical formulae, however the chemical and physical properties of the secretion by the mantle assume to differ slightly or greatly from species to species. While the orientation of calcium carbonate crystals is agreed well with the horizontal growth direction of shells $11,2,4), 61$, and must be accompanied by the elongation and tension of the mantle during growth of animals. That is, their orientation also assumes to have close relation to the growth axes of animals which are pointed out by $\mathrm{YoNGE}^{8)}$, and to be considerably affected by the local positions of attachment of adductor muscle or pallial and pedal ones by which the mantle and body are attached to the shell. Seemingly, the orientation of crystallographical axes is not always coincided with the growth axes of animals but is considered to be nearly parallel to the growth of lamellae in local areas of shells. It is, in any case, probable that mineral crystals deposit epitaxially with organic matrix in the definite direction according to physical formulae in the processes of shell mineralization. On the other hand, the author thinks that the forms and ornaments of shells would be more perfectly provided with such biological formulae as volution and adaptation of animals to environments surrounding them.

\section{Summary}

1) Growth hills occurred on the inner surface of the Ostrea shell were a stepped pyramidal one consisting of accumulation of foliated calcite crystals, one of the rhombohedral axes of which radiated spirally or directly outwards from the top of hills and appeared to coincide with the direction of growth of individuals.

2) Crystal habit of the calcite in the Ostrea shell was similar to that of the calcite in the Anomia shell.

3) The limiting factors on crystal orientation in molluscan shells were discussed.

\section{References}

1) Rama, S. S.: Proc. Ind. Acad. Sci., 1, 871 (1935).

2) SchmidT, W. J.: Zool. Jahrb., 45, 110 (1924).

3) TujI, T., Sharp, D. G. and Wilbur, K. M.: J. Biophsic. and Biochem. Cytol., 4, 275 (1958).

4) WadA, K.: Bull. Natl. Pearl Res. Lab., 7, 703 (1961).

5) —: Bull. Jap. Soc. Sci. Fish, 29, 320 (1963).

6) —_._. Venus (printing).

7) Watabe, N., Sharp, D. G. and WIlbur, K. M.: J. Biophysic. and Biochem. Bytol., 4, 281 (1958).

8) Yonge, C. M.: Trans. Royal Soc. Edinburgh, LXII-II-(12), 443 (1953). 